УДК: 338.48

DOI 10.18101/2304-4446-2020-1-20-28

\title{
РАЗВИТИЕ ЭТНОГРАФИЧЕСКОГО ТУРИЗМА В РОССИИ: АНАЛИЗ РЕГИОНАЛЬНЫХ ПРОЕКТОВ
}

\author{
(C) Максанова Людмила Бато-Жаргаловна
}

доктор экономических наук, доцент

E-mail:1maksanova@yandex.ru

(c) Хандажапова Любовь Михайловна

кандидат экономических наук, доцент

E-mail:khanl@yandex.ru

\section{(C) Еремко Зинаида Сергеевна}

ведущий инженер

E-mail: zina--90@mail.ru

\section{(C) Ботоева Надежда Бимбаевна}

инженер

E-mail: nadezhdabotoeva@yandex.ru

(C) Бадмаева Арюна Солбоновна

секретарь по международным связям

E-mail: inter@binm.ru

Байкальский институт природопользования СО РАН

Россия, 670047, г. Улан-Удэ, ул. Сахьяновой, 6

В статье представлены результаты изучения и оценки совокупности проектов развития этнографического туризма в регионах России. Методологический инструментарий оценки и выявления лучших региональных практик этнографического туризма разработан на основе многоуровневой системы критериев. Дана сравнительная оценка проектов этнографического туризма регионов России. Определены лучшие региональные практики этнографического туризма. Обоснован вывод о необходимости распространения опыта лучших практик в сфере обеспечения инфраструктурными услугами, планирования и управления, обеспечения качества и безопасности туристических услуг, маркетинга и продвижения этнотуристского продукта. Практическая значимость предлагаемого авторами методологического инструментария оценки региональных проектов этнографического туризма заключается в возможности его применения не только на российском уровне, но и региональном и муниципальном уровнях управления развитием туризма.

Ключевые слова: этнографический туризм; регион; историко-культурный потенциал; метод анализа иерархий; критерии; лучшая практика.

\section{Для цитирования}

Максанова Л. Б.-Ж., Хандажапова Л. М., Еремко 3. С., Ботоева Н. Б., Бадмаева А. С. Развитие этнографического туризма в России: анализ региональных проектов // Вест-

\footnotetext{
${ }^{1}$ Статья подготовлена при финансовой поддержке Российского фонда фундаментальных исследований (проект № 18-010-00881).
} 
Л. Б.-Ж. Максанова, Л. М. Хандажапова, З. С. Еремко, Н. Б. Ботоева, А. С. Бадмаева. Развитие этнографического туризма в России: анализ региональных проектов

ник Бурятского государственного университета. Экономика и менеджмент. 2020. № 1

С. 20-28.

В Повестке дня Организации Объединенных Наций в области устойчивого развития на период до 2030 г. обозначена высокая прогрессивная роль туризма в популяризации культурных ценностей и наследия и создании миролюбивых и открытых обществ в интересах устойчивого развития. Для достижения этих целей многие страны содействуют расширению путешествий, включающих знакомство с народными обычаями и ремеслами, бытом и традициями, с историей и творчеством коренных народов, проживающих на территориях этих стран [1].

Суть данного вида туризма, активно обсуждаемого в научной литературе, описывается разнообразными терминами, а именно: этнографический, этнический, этнокультурный, этноэкологический, фольклорно-этнографический, аборигенный и другие. Считается, что два первых термина используются чаще всего, а в некоторых случаях рассматриваются как синонимы. В отечественной туристике широкое распространение получил термин «этнографический туризм». При этом многие исследователи определяют его как вид культурно-познавательного туризма, основной целью которого является посещение этнографического объекта для знакомства с культурой, архитектурой, бытом и традициями народа, этноca, проживающего сейчас или проживавшего когда-либо на данной территории [2-4].

Российская Федерация располагает колоссальным потенциалом развития этнографического туризма. Прежде всего его основу составляет историкокультурное наследие и этнокультурное многообразие 193 народов России. В государственном реестре памятников истории и культуры РФ числится 84545 объектов культурного, природного и исторического наследия, в том числе 28 объектов Всемирного наследия ЮНЕСКО. К историческим городам и поселениям относятся 539 поселений, в которых сохраняются не только отдельные памятники истории и культуры, но и памятники градостроительства, архитектурные ансамбли, образцы исторической застройки и исторические ландшафты. В стране насчитывается 2700 государственных и муниципальных музеев в 477 городах, в которых хранится 80 млн музейных предметов, 103 музея-заповедника, 41 музейусадьба, 63 дворцово-парковых ансамбля ${ }^{1}$.

Рынок этнотуризма в России оценивается в полмиллиона человек ${ }^{2}$. Во многих российских регионах приоритетность развития этнографического туризма подтверждена реальными действиями и вполне ощутимыми результатами. Прежде всего это формирование этнографических маршрутов, развитие музеевзаповедников, этнокультурных центров, этнодеревень, проведение событийных мероприятий и пр. Созданы реестры этнографических объектов и маршрутов, осуществляются методическая, консультационная, информационная, организационная поддержка предпринимателей, занимающихся оказанием услуг, действует процедура добровольной сертификации услуг этнографического туризма и т. д. Определяющими при разработке и реализации этнографических туров яв-

\footnotetext{
1 Лучшие практики этнографического туризма в Российской Федерации. М.: Изд-во Рос. экон. ун-та им. Г. В. Плеханова, 2018. С. 10.

2 Там же. С. 11.
} 
ляются инициатива бизнесменов, вовлечение местного населения и активная поддержка со стороны органов региональной и муниципальной власти. Проекты этнографического туризма в регионах имеют разное тематическое наполнение и масштаб развития. Однако практически отсутствует межрегиональное сравнение эффективности проектов этнографического туризма, что в значительной степени объясняется неразработанностью методологического инструментария их оценки.

Авторами создана система критериев и предложен алгоритм, который позволяет оценивать уровень управления, качества, безопасности, развития инфраструктуры, экономической эффективности и реализуемости проектов развития этнографического туризма. В основу алгоритма оценки, ранжирования и выявления лучших проектов этнографического туризма положен зарекомендовавший себя в практике метод анализа иерархий [5; 6]. Алгоритм включает в себя три этапа. На первом этапе осуществляется анализ региональных туристических проектов (рис. 1, этап 1) на примере 129 проектов этнографического туризма из 55 регионов России.

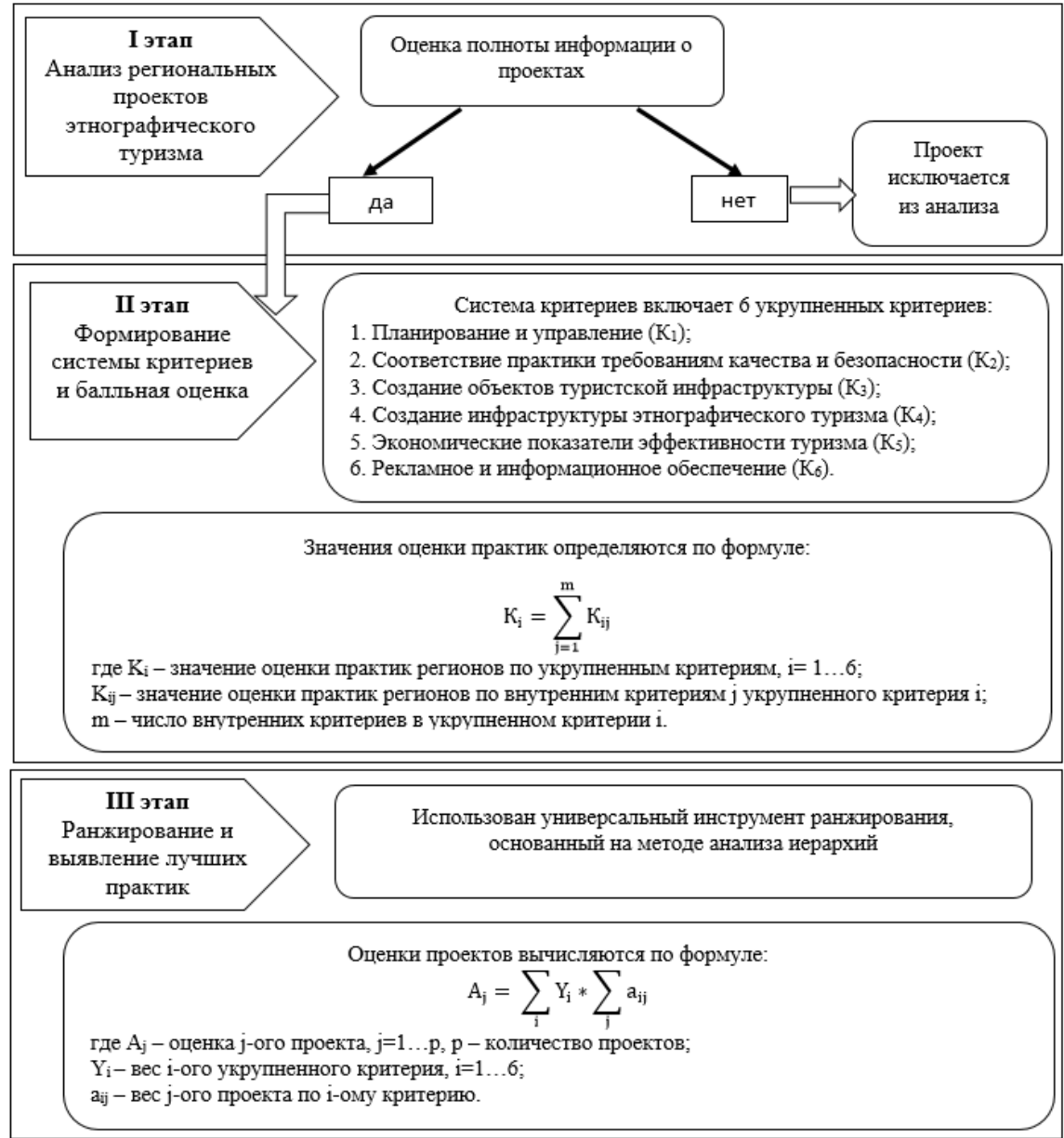

Рис. 1. Алгоритм оценки региональных проектов и выявления лучших практик этнографического туризма. Источник: составлено авторами 
Л. Б.-Ж. Максанова, Л. М. Хандажапова, З. С. Еремко, Н. Б. Ботоева, А. С. Бадмаева. Развитие этнографического туризма в России: анализ региональных проектов

На следующем этапе каждый проект сначала рассматривается с позиций соответствия системе критериев, затем осуществляется балльная оценка проектов по укрупненным критериям (рис. 1, этап 2). Система критериев включает в себя совокупность 6 укрупненных критериев $\left(\mathrm{K}_{1}-\mathrm{K}_{6}\right)$, по каждому из которых распределено 32 внутренних критерия, позволяющих более точно оценить степень соответствия конкретного проекта укрупненному критерию (табл. 1).

Таблица 1

Система критериев оценки региональных проектов развития этнографического туризма

\begin{tabular}{|c|c|}
\hline $\begin{array}{l}\text { Укрупненные } \\
\text { критерии }\end{array}$ & Внутренние критерии \\
\hline $\begin{array}{l}\text { Планирование и } \\
\text { управление }\left(K_{1}\right)\end{array}$ & 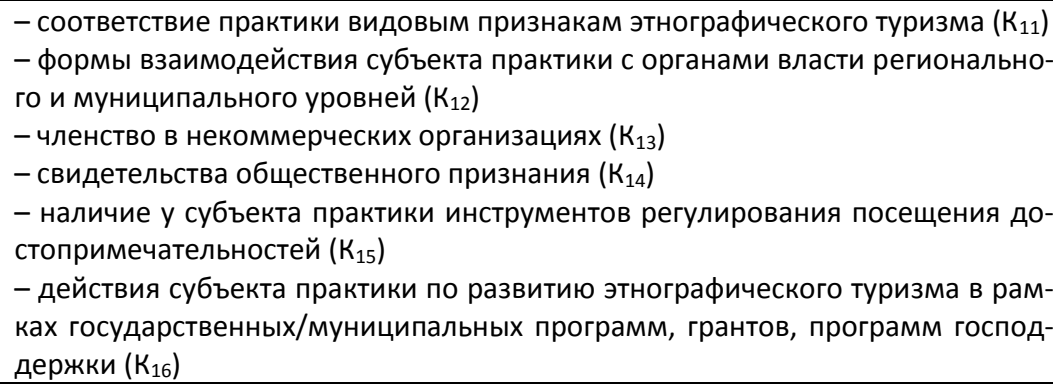 \\
\hline $\begin{array}{l}\text { Соответствие } \\
\text { практики требо- } \\
\text { ваниям качества } \\
\text { и безопасности } \\
\left(\mathrm{K}_{2}\right)\end{array}$ & 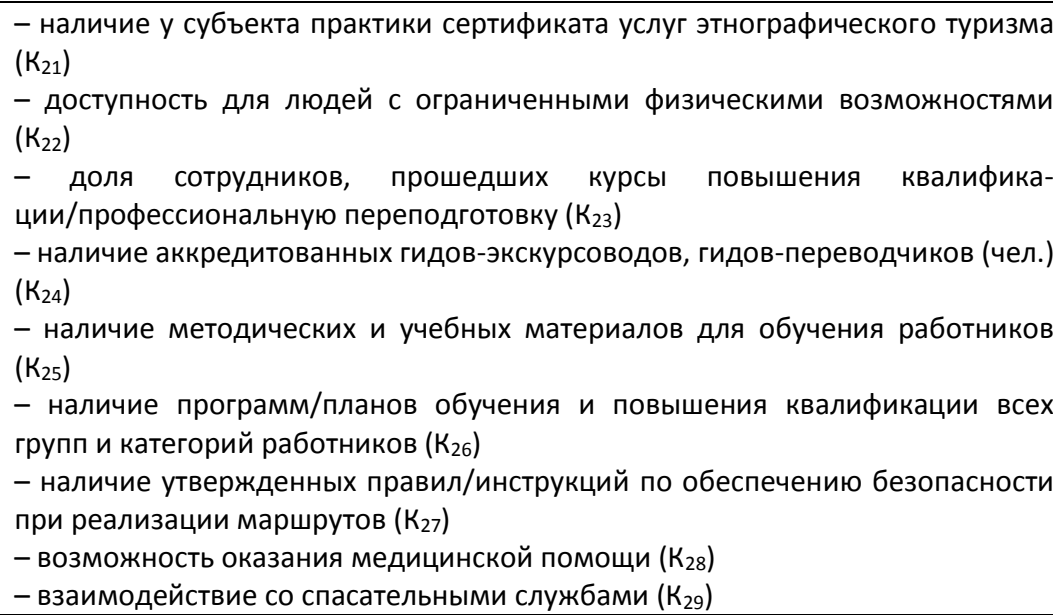 \\
\hline $\begin{array}{l}\text { Создание объектов } \\
\text { туристской инфра- } \\
\text { структуры (Кз) }\end{array}$ & $\begin{array}{l}\text { - наличие собственных средств размещения }\left(K_{31}\right) \\
\text { - наличие собственных пунктов общественного питания }\left(K_{32}\right)\end{array}$ \\
\hline $\begin{array}{l}\text { Создание инфра- } \\
\text { структуры этно- } \\
\text { графического } \\
\text { туризма }\left(\mathrm{K}_{4}\right)\end{array}$ & $\begin{array}{l}\text { - ремесленные мастерские }\left(K_{41}\right) \\
\text { - элементы традиционного быта }\left(K_{42}\right) \\
\text { - краеведческий музей }\left(K_{43}\right) \\
\text { - национальные центры }\left(K_{44}\right) \\
\text { - конное подворье }\left(K_{45}\right) \\
\text { - смотровые площадки }\left(K_{46}\right) \\
\text { - пункты фотографирования }\left(K_{47}\right) \\
\text { - визит-центры }\left(K_{48}\right) \\
\text { - другие объекты }\left(K_{49}\right)\end{array}$ \\
\hline $\begin{array}{l}\text { Экономические } \\
\text { показатели }\left(\mathrm{K}_{5}\right)\end{array}$ & $\begin{array}{l}\text { - динамика официально зарегистрированных посетителей }\left(K_{51}\right) \\
\text { - общее количество сотрудников на объекте этнографического туризма }\left(K_{52}\right)\end{array}$ \\
\hline
\end{tabular}




\begin{tabular}{|c|c|}
\hline & $\begin{array}{l}\text { - инвестиции в основной капитал инфраструктуры объекта этнографического } \\
\text { туризма (тыс. р.) (К } \\
\text { - объем платных услуг (тыс. р.) }\left(K_{54}\right)\end{array}$ \\
\hline $\begin{array}{l}\text { Рекламное и } \\
\text { информационное } \\
\text { обеспечение } \\
\text { этнографического } \\
\text { туризма }\left(\mathrm{K}_{6}\right)\end{array}$ & - информационное обеспечение услуг этнографического туризма $\left(K_{61}\right)$ \\
\hline
\end{tabular}

Источник: составлено авторами

Значения оценки региональных практик этнографического туризма по выделенным укрупненным критериям определяются по формуле, представленной на рис. 1, этап II.

Значения оценки проекта по внутренним критериям ј укрупненного критерия $\mathrm{i}$ $\left(\mathrm{K}_{\mathrm{ij}}\right)$ определяются экспертным методом:

- максимальный балл, равный 1 , присваивается внутреннему критерию, если выполнены все условия, необходимые для соответствия выбранному критерию;

- средний балл, значение которого может меняться в интервале от 0,5 до 0,7, присваивается по соответствующему критерию (для отдельных критериев - при наличии), если выполнена большая часть условий, необходимых для соответствия выбранному критерию;

- минимальный балл, равный 0 , присваивается в случае невозможности получения более высокого балла (по причине отсутствия подтверждающих сведений, невозможности установления однозначного соответствия и т. п.).

Значение общей балльной оценки каждого проекта по каждому из укрупненных критериев определяется по сумме баллов критериев внутри группы. При определении балльной оценки укрупненного критерия К 4 используется значение балла, равное 0,1 , за каждый объект инфраструктуры этнографического туризма.

На заключительном этапе проводится ранжирование и выявление лучших практик (рис. 1, этап 3). Представленная в таблице 1 критериальная база исследования включает в себя разные по значимости базовые критерии, что предопределило их ранжирование и формирование шкалы оценки, позволяющей экспертным путем оценить степень важности критериев: от -1 (равная значимость) до -9 (абсолютное превосходство).

Для определения значимости критериев формируются так называемые матрицы парных сравнений, где каждому из критериев присваивается число в интервале от 1-9. Веса критериев, как результаты экспертных оценок, показывают, во сколько раз один проект полезнее другого по данному укрупненному критерию.

Для выявления лучших практик регионов по развитию этнографического туризма сначала определяется значимость проектов по каждому из укрупненных критериев. Схема процесса принятия решения в рамках этого этапа представляет собой процедуру построчного заполнения экспертом матриц парных сравнений, строки и столбцы которых содержат названия проектов. Количество матриц равно количеству укрупненных критериев. Затем для каждого вектора оценок проектов вычисляются веса проектов, что представляет собой соответствующую строку матрицы решений. Формула для вычисления оценки проектов представлена на рис. 1, этап III. 
Л. Б.-Ж. Максанова, Л. М. Хандажапова, З. С. Еремко, Н. Б. Ботоева, А. С. Бадмаева. Развитие этнографического туризма в России: анализ региональных проектов

Таким образом, после проведения серии из m попарных сравнений (по числу укрупненных критериев) для каждого проекта из заполненной матрицы решений можно определить векторы оценок проектов, которые свертываются в оценку полезности проектов. Лучшим считается проект с максимальным значением.

Были определены веса 6 укрупненных критериев. Наиболее значимыми являются: критерий, характеризующий уровень планирования и управления $\left(\mathrm{K}_{1}=\right.$ $0,305)$, критерий, характеризующий соответствие практики требованиям качества и безопасности $\left(\kappa_{2}=0,250\right)$, критерий, характеризующий уровень создания инфраструктуры этнографического туризма $\left(K_{4}=0,194\right)$, критерий, характеризующий создание объектов туристской инфраструктуры $\left(\kappa_{3}=0,138\right)$, критерий, характеризующий экономические показатели $\left(K_{5}=0,083\right)$, критерий, характеризующий уровень рекламного и информационного обеспечения $\left(\kappa_{6}=0,020\right)$.

Расчеты выполнены на основе программного продукта для ЭВМ № 2018610966 «Региональные особенности реализации инвестиционных проектов» ${ }^{1}$.

Исследование показало, что организацией этнографического туризма в российских регионах занимаются дирекции особо охраняемых природных территорий, субъекты туристской индустрии, бюджетные учреждения, коммерческие организации, индивидуальные предприниматели, физические лица, общественные организации, в том числе родовые общины коренных малочисленных народов. При этом $66,7 \%$ организаций относятся к государственным или муниципальным бюджетным учреждениям в сфере культуры, образования и пр.; $20,3 \%$ - к предпринимательскому сообществу; $10,6 \%$ - общественному сектору и $2,4 \%$ являются физическими лицами.

В число лучших региональных практик по развитию этнографического туризма вошло 60 проектов, в таблице 2 представлено ТОП-10 лучших региональных практик итогового рейтинга.

Так же, как и в развитии экологического туризма [7], большее число лучших этнотуристских практик отмечено в регионах, которые не только располагают ценными ресурсами, современной туристской инфраструктурой, но и применяют системный подход к развитию этнографического туризма.

На многих этнографических объектах действуют правила посещения территорий и экспозиций музейных комплексов, этнокультурных центров. Для памятников деревянного зодчества предусмотрен особый режим посещения с ограничением предельного числа посетителей. $60,5 \%$ этнографических объектов из общего числа рассматриваемых проектов доступны для людей с ограниченными физическими возможностями. На территории многих музеев-заповедников расположена информационно-навигационная система (информационные стенды с картами и краткой информацией о секторе музея/объекте), установлены указатели. Особое внимание уделяется соблюдению правил обеспечения безопасности при проведении экскурсий и событийных мероприятий.

1 Свидетельство о государственной регистрации программы для ЭВМ №2018610966 Региональные особенности реализации инвестиционных проектов / 3. С. Еремко, С. Н. Аюшеева; заявитель и правообладатель ФГБУН «Байкальский институт природопользования СО РАН». — № 201761 7200/69 заявл. 21.07.2017; опубл. 19.01.2018. 
Таблица 2

ТОП-10 лучших региональных практик по развитию этнографического туризма

\begin{tabular}{|c|c|c|c|c|c|c|c|c|}
\hline Субъект РФ & $\begin{array}{c}\text { Название } \\
\text { лучшей практики, } \\
\text { (ранг) }\end{array}$ & 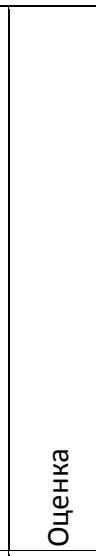 & 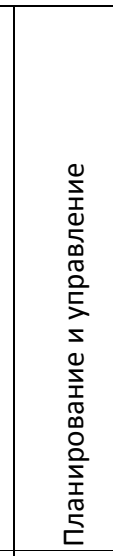 & 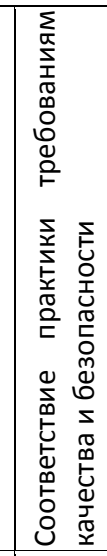 & 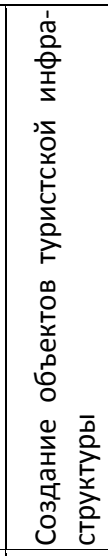 & 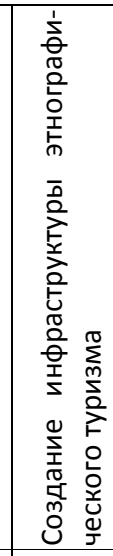 & 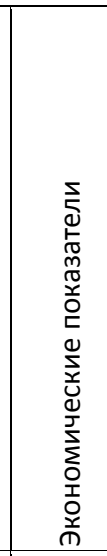 & 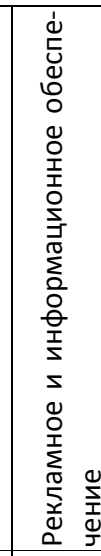 \\
\hline $\begin{array}{l}\text { Республика } \\
\text { Карелия }\end{array}$ & $\begin{array}{l}\text { Государственный истори- } \\
\text { ко-архитектурный и этно- } \\
\text { графический музей- } \\
\text { заповедник «Кижи» (1) }\end{array}$ & 0.0157 & 0.0166 & 0.0165 & 0.0153 & 0.0143 & 0.0165 & 0.0085 \\
\hline $\begin{array}{l}\text { Оренбургская } \\
\text { область }\end{array}$ & $\begin{array}{l}\text { Интерактивный музей } \\
\text { казачьей культуры «Каза- } \\
\text { чий курень» (2) }\end{array}$ & 0.0152 & 0.0163 & 0.0133 & 0.0153 & 0.0167 & 0.0165 & 0.0085 \\
\hline $\begin{array}{l}\text { Республика } \\
\text { Бурятия }\end{array}$ & $\begin{array}{l}\text { Этнокомплекс «Степной } \\
\text { кочевник» (3) }\end{array}$ & 0.0147 & 0.0167 & 0.0157 & 0.0059 & 0.0159 & 0.0139 & 0.0085 \\
\hline $\begin{array}{l}\text { Удмуртская } \\
\text { Республика }\end{array}$ & $\begin{array}{l}\text { Архитектурно-этногра- } \\
\text { фический музей-заповед- } \\
\text { ник «Лудорвай» (4) }\end{array}$ & 0.0141 & 0.0142 & 0.0133 & 0.0127 & 0.0159 & 0.0154 & 0.0085 \\
\hline $\begin{array}{l}\text { Красноярский } \\
\text { край }\end{array}$ & $\mid \begin{array}{l}\text { Историко- } \\
\text { этнографический музей- } \\
\text { заповедник «Шушенское» } \\
\text { (5) }\end{array}$ & 0.0137 & 0.0157 & 0.0157 & 0.0059 & 0.0119 & 0.0139 & 0.0085 \\
\hline $\begin{array}{l}\text { Республика } \\
\text { Чувашия }\end{array}$ & $\begin{array}{l}\text { Этноэкологический ком- } \\
\text { плекс «Ясна» (6) }\end{array}$ & 0.0137 & 0.0126 & 0.0133 & 0.0153 & 0.0143 & 0.0159 & 0.0085 \\
\hline $\begin{array}{l}\text { Псковская } \\
\text { область }\end{array}$ & $\mid \begin{array}{llr}\text { Государственный } & \text { истори- } \\
\text { ко-архитектурный } & \text { и } \\
\text { родри- } \\
\text { зей-запоповеднафный } \\
\text { (7) }\end{array}$ & 0.0137 & 0.0121 & 0.0157 & 0.0153 & 0.0143 & 0.0113 & 0.0085 \\
\hline $\begin{array}{l}\text { Республика } \\
\text { Бурятия }\end{array}$ & $\begin{array}{l}\text { Этнографический маршрут } \\
\text { «В гостях у староверов» (8) }\end{array}$ & 0.0135 & 50.0148 & 0.0165 & 0.0153 & 0.0057 & 0.0154 & 0.0085 \\
\hline $\begin{array}{l}\text { Пермский } \\
\text { край }\end{array}$ & $\begin{array}{l}\text { Архитектурно- } \\
\text { этнографический } \\
\text { «Хохловка» (9) } \\
\end{array}$ & 0.0135 & 50.0142 & 0.0153 & 0.0059 & 0.0167 & 0.0092 & 0.0085 \\
\hline \begin{tabular}{|l|} 
Архангельская \\
область
\end{tabular} & $\begin{array}{l}\text { Национальный парк «Ке- } \\
\text { нозерский» (10) }\end{array}$ & 0.0135 & 50.0150 & 0.0111 & 0.0127 & 0.0159 & 0.0139 & 0.0085 \\
\hline
\end{tabular}

Источник: составлено авторами 
Л. Б.-Ж. Максанова, Л. М. Хандажапова, З. С. Еремко, Н. Б. Ботоева, А. С. Бадмаева. Развитие этнографического туризма в России: анализ региональных проектов

Практически во всех представленных региональных практиках, прежде всего в музеях, разработаны планы обучения и повышения квалификации работников, подготовлены методические и учебные материалы, осуществляется сотрудничество с научно-образовательными учреждениями.

Лучшие практики отличаются вовлечением местного населения в развитие этнографического туризма; привлечением и обучением специалистов, экскурсоводов из числа местных жителей; развитием местных ремесел и производством сувениров. Положительным фактором является формирование социальной ответственности туроператоров (Красноярский край, Республика Чувашия и др.), добровольно сертифицирующих туристические услуги и маршруты.

Большинство региональных проектов этнографического туризма получило общественное признание, что является подтверждением организации ими качественных и безопасных этнографических туров и рекомендацией для их продвижения и тиражирования.

Результаты исследования свидетельствуют о том, что методологический подход к оценке региональных проектов этнографического туризма, основанный на многоуровневой системе критериев, позволяет провести анализ, сравнить проекты по разным критериям и выявить лучшие. Накопленный регионами опыт в сфере развития этнотуризма свидетельствует как о региональной специфике, так и общих подходах при разработке проектов, реализующих этнокультурный потенциал. Данный опыт может быть интересен и полезен для территорий, которые стремятся создать почву для устойчивого развития этнографического туризма.

Повышение роли и вклада этнографического туризма в продвижение индустрии туризма к стандартам устойчивого развития определяет необходимость углубления подобных тематических исследований в целях обобщения передового опыта и повышения качества управления реализацией проектов этнографического туризма.

\section{Литература}

1. Jean Junying Lor, Shelly Kwa, John A. Donaldson. Making ethnic tourism good for the poor // Annals of Tourism Research. 2019. Vol. 76. Pp. 140-152.

2. Охотина М. Н. Развитие этнографического туризма в Республике Марий Эл // Современные проблемы сервиса и туризма. 2016. Т. 10, № 3 . С. 73-78.

3. Трофимов Е. Н. Развитие этнографического туризма в России // Этносоциум и межнациональная культура. 2015. № 3(81). С. 9-17.

4. Сундуев Ч. Б., Хышиктуева Л. В. Этнотуризм как одно из направлений культурнопознавательного туризма // Вестник Бурятского государственного университета. 2009. № 4. C. 53-56.

5. Бардаханова Т. Б., Еремко 3. С., Максанова Л. Б.-Ж. Методический подход к оценке, ранжированию и выявлению лучших проектов в сфере экологического туризма // $\mathrm{Pe}-$ гиональная экономика: теория и практика. 2019. Т. 17, № 4(463). С. 789-800.

6. Рожкова Н. В. Туризм. Изучение факторов его развития с помощью методов анализа иерархий и нечеткого логического вывода // Вестник Финансового университета. 2016. Т. 20, № 4(94). C.84-88.

7. Ecotourism Development in Russia: Analysis of Best Regional Practices / E. A. Dzhandzhugazova [and etc.] // Ekoloji. 2019. T. 28, № 107. C. 411-415. 


\section{DEVELOPMENT OF ETHNOGRAPHIC TOURISM IN RUSSIA: AN ANALYSIS OF REGIONAL PROJECTS}

Lyudmila B.-Zh. Maksanova

Dr. Sci. (Econ.), A/Prof.

E-mail: lmaksanova@yandex.ru

Lyubov M. Khandazhapova

Cand. Sci. (Econ.), A/Prof.

E-mail: khanl@yandex.ru

Zinaida S. Eryomko

Leading Engineer

E-mail: zina--90@mail.ru

Nadezhda B. Botoeva

Engineer

E-mail: nadezhdabotoeva@yandex.ru

Aryuna S. Badmaeva

Secretary for International Relations

E-mail: inter@binm.ru

Baikal Institute of Nature Management SB RAS

6 Sakhyanovoy St., Ulan-Ude 670047, Russia

The article presents the results of the study and assessment of a set of projects for the development of ethnographic tourism in the regions of Russia. Methodological tools for assessing and identifying the best regional practices of ethnographic tourism have been developed on the basis of a multi-level system of criteria. We gave a comparative assessment of ethnographic tourism projects in Russian regions and determined the best regional practices of ethnographic tourism. It was concluded that there is a necessity for dissemination of the best practices in infrastructure services, planning and management, ensuring the quality and safety of tourism services, marketing and promoting ethno-tourist products. The practical significance of the methodological tools proposed by us for assessing regional ethnographic tourism projects lies in the possibility of its application not only at the Russian level, but also at the regional and municipal levels of tourism development management.

Keywords: ethnographic tourism; region; historical and cultural potential; hierarchy analysis method; criteria; best practice. 